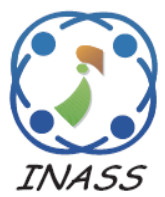

\title{
A Study on High-Speed Rail Pricing Strategy for Thailand Based on Dynamic Optimal Pricing Model
}

\author{
Somkiat Khwanpruk ${ }^{1} \quad$ Chalida U-tapao $^{1} \quad$ Kankanit Khwanpruk $^{2}$ \\ Laemthong Laokhongthavorn $^{1} \quad$ Seksun Moryadee $^{3 *}$
}

${ }^{1}$ Department of Civil Engineering, King Mongkut's Institute of Technology Ladkrabang, Bangkok Thailand, 10520

${ }^{2}$ Department of Food Engineering, King Mongkut's Institute of Technology Ladkrabang, Bangkok Thailand, 10520

${ }^{3}$ Department of Ordnance Engineering, Chulachomklao Royal Military Academy, Nakon Nayok, Thailand 260,01

* Corresponding author’s Email: seksun.mor@gmail.com

\begin{abstract}
The Bangkok-Nong Khai high-speed railway is the first high-speed line in Thailand and is currently under construction. The project is due to be completed by 2023, with ticket prices starting at 80 baht plus 1.8 baht per km which can be considered as a straight-line fare set with a fixed rate increase. Different from the current price policy, this paper examines the application of dynamic pricing to Thailand's HSR. Dynamic Pricing Optimizer proposed in this paper is a unique system of dynamic pricing by considering the changes in the amount of service requirements and the time of purchasing tickets designed to solve the problem of pricing that is appropriate. First, The Dynamic Pricing Optimizer (DPO) system will integrate the user data from the latest trip or historical information. After that, there will be a forecast for users of high-speed trains based on historical data in order to create a demand function that is linear. After that, the price will be determined by the optimization method to find the most suitable price in order to maximize the revenue. Lastly, we compare both fare policies and found that The Dynamic Pricing policy can increase revenue up to $6.5 \%$.
\end{abstract}

Keywords: Dynamic pricing, Mathematical model, High-speed train.

\section{Introduction}

In the implementation of the Thai logistics system development plan 2017-2021, There is one strategy that can be considered as an important strategy for driving and developing the logistics system in Thailand i.e. Strategy 7: Development of Infrastructure and Logistics System of The Country which the investment is considered as a strategic investment of the country. The project implementation is cooperation between the Government of the Kingdom of Thailand and the Government of the People's Republic of China in the development of high-speed rail systems to link the region between Bangkok-Nong Khai province (Phase 1: Bangkok-Nakhon Ratchasima province) which will be strategically important in linking the logistics system of Thailand with the ASEAN region and the People's Republic of China that currently has the largest economic size in the region and also have high trade, investment and tourism value with Thailand as a part of the One Belt One Road strategy. Moreover, to support the strategy of creating Thailand as a regional transportation and logistics hub for promoting the economic and social development strategies of the northeastern region to be linked with the special economic development project in eastern region including linking Thailand with the People's Republic of China. Therefore, this project is important to the prosperity of Thailand in the long term.

Besides the overall benefits that will occur with the context of connecting the logistics routes of Thailand and abroad, Thai-Chinese high-speed rail development project for Bangkok - Nong Khai route which the government is developing as a project that supports economic trade and investment growth, and expands the prosperity from the center to various 
major cities as well as fulfilling Thailand into the ASEAN Economic Community. That is, there is a rail transport system that can connect to neighboring countries by the Bangkok-Nong Khai railway route that has a total of 5 stations (excluding Nakhon Ratchasima station which is a part of the BangkokNakhon Ratchasima route) including Bua Yai, Ban Phai, Khon Kaen, Udon Thani, Nong Khai. The total distance is 355 kilometers

One factor that has influenced the success of the country's strategic investment by using high-speed rail systems as a driver is pricing the fare to be appropriate, fair and able to attract users to use the service. In terms of fare planning and train schedule, the government plans to collect fares starting at 80 baht (Fixed Rate) and adding 1.8 baht per kilometer (Variable Rate) such as a fare by traveling from Bangkok to Nakhon Ratchasima is equal to $80+1.8$ $(96.1)=253$ baht which can be considered as a straight-line fare, i.e.

Fare $=$ Fixed rate + Distance in kilometers $\mathrm{X}$ Variable rate per kilometer

Furthermore, it will increase by 15 percent every 5 years due to the forecast of the passenger volume. The government has planned to operate the train with stops at every station, providing a service with a maximum speed of 250 kilometers/hour with the distance of 253 kilometers in 6 stations and stops for 2 minutes at each station, total travel time is about 1 hour 30 minutes. The service period is $6.00-22.00$ hrs. or 16 hours per day. In the first year of service (year 2021), there will be 11 trains per day per direction with a service frequency of 90 minutes/train.

At present, there are many types of fare pricing models that are commonly used such as dynamic pricing according to Fig. 1 that is currently used to book tickets for various airlines which the price will be related to other information such as the amount of demand for the service in that time, service time or the time of booking tickets. Service rates may be adjusted frequently in every hour or every day, depending on the management system.

According to the forecast of the initial government's fare rates, it is very interesting to study and create knowledge in the structure of the fare rate and the determination of fair fares and optimal pricing to enable the high-speed rail operation to benefit users. Likewise, can generate income that is suitable for an investment. Beyond, another important aspect of pricing is price determination that does not only directly affect users but also affect other transport operators such as bus operators, aviation operators, and operators of various product delivery. Therefore, the researcher is interested in
Dynamic Pricing
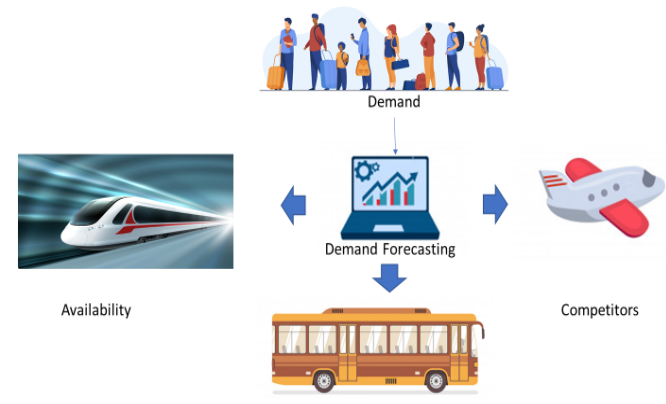

Figure. 1 Dynamic pricing model ${ }^{1}$

studying the fare structure and the creation of a dynamic pricing optimization model to find the appropriate fares and proceed to find a comparison with High-speed train fares that are expected from the government and provide policy recommendations in the pricing strategy of the country's high-speed rail fares for the maximum benefit of the country by dividing the research topic into 2 research points as follows.

- A Review of High-Speed Train Pricing and Structure of Prices

This study aims to study the model of fares of high-speed rail systems in various countries. In addition, also want to find out why each country uses that fare structure and find the comparison of the price structure in each model.

- Optimal High-Speed Train Pricing- New Scheme of Dynamic Pricing Using Mathematical Model

This research aims to study the form of determining the fares of high-speed trains used in various countries and guidelines for determining the strategy for determining fares by using mathematical models for high-speed rail systems, Bangkok-Nong Khai route. The main objective topics are as follows.

- To study the fares model of the high-speed train system samples in various countries. In addition, also want to find out why each country uses that fare structure and find a comparison of the price structure in each model.

- To study the relationship between demand quantity for high-speed train service and pricing in various forms.

- To create the optimal dynamic pricing model that is used to determine the price of highspeed trains with the goal of providing a flexible and fair price while increasing revenue for high-speed rail operations.

- To compare between the fare that uses the dynamic pricing optimization model and the 
high-speed train fare that are expected from the government.

- To establish policy guidelines of fare pricing for high-speed rail systems in order to benefit the overall public transportation system development in Thailand which is consistent with the amount of demand from the public and private sectors in all sectors.

The main contributions in this paper are threefold. This paper develops a novel, linear program to create an optimal dynamic pricing model that is used to determine the price of high-speed trains for attracting users while increasing revenue for highspeed rail operations. The method of pricing based on government's expectation which is less flexible that may lead to loss of profits during the high season of travel. Therefore, setting a dynamic pricing model can be able to determine the price which is more suitable for the situation in that period. When creating the model successfully, it will be compared between the new pricing model and the government pricing model (policy analysis based on new pricing scheme of dynamic pricing). This optimization framework is generalizable and can be applied for other studies.

Second, the paper develops Dynamic Pricing Optimizer (DPO) is a unique system of dynamic pricing by considering the changes in the amount of service requirements and the time of purchasing tickets designed to solve the problem of pricing that is appropriate. DPO consists of Demand Forecasting Module and Dynamic Pricing Module. Lastly, we apply to the case study of Thai Rail system to analyze and compare with the current pricing policy.

\section{Literature reviews}

\subsection{Dynamic pricing}

Dynamic Pricing also known as Time-Based Pricing or Demand Pricing that is a flexible pricing strategy based on factors such as demand quantity, time requirements, market mechanisms [1, 2]. Dynamic pricing strategy started in the United States in the early 80s [3] during the period of free trade that the state will oversee a business competition but will let the price change according to the market mechanism. Therefore, dynamic pricing is widely used in the industrial sector. The aviation business is the first business that uses the pricing strategy of dynamic pricing to increase revenue for the organization which later became widely used in many sectors such as transportation, aviation sector: ticket prices, tourism sector: hotel prices and movie tickets prices, and energy sector: electricity pricing that operators will use different methods to adjust the price of their products and services $[4,5,6]$. In addition, dynamic pricing strategy can be used as a pricing strategy for revenue management. The aim of revenue management is to make the highest income by selling the right product or service to the right customers at the right time with a reasonable price to achieve the highest income.

The research of dynamic pricing which related to fare pricing is widely used mathematical models. The interesting researches are as follows.

[7] M. Labbé et.al, used the Bi-Level program to set up the express fare (Toll-Setting) and applied the model to the sample and can find the solution for the small problems because the model is complicated to find the answer.[8] K. Van Dender created a mathematical model with a fixed price and variable prices by determining the price factors from the distance and the station location[9] L.S. Buriol et.al, created a mathematical model by dividing the best answers into 2 steps: first, finding the best answer for the transportation assignment problem, after that, use the answers in the first step to carry out the toll pricing problem. The goal is for all travelers to get the most benefit. T. van Woensel et.al, created a stochastic model to determine the toll price that considered the uncertainty that would occur due to the receiving a service. E.T. Verhoef applied the mathematical model to find the toll price in the General Static Transportation Networks with a flexible amount of demand.

\subsection{Demand forecasting}

Demand Forecasting is an activity related to many parties in the organization. Marketing is the first department that deals with forecasting the number of users which is related to the impact on many activities both in terms of service capabilities and allocating resources in a timely manner to respond to customers. Demand forecasting is commonly used in 3 ways:

2.2.1 Direct consumer survey is an estimate of demand by asking or interviewing directly with consumers.

2.2.2 Market experiment is an estimate of demand from data collection which retrieved from the behavior of consumers towards their products when the business has changed some policies such as new product updates, advertising and new associations, etc.

2.2.3 Regression analysis is a statistical method used to describe a relationship between dependent 
variables and independent variables systematically and have a test principle to build a confidence of the results because they can study the relationship between product demand and various variables which have an influence on the demand determination.

\section{Optimization Modelling}

Optimization Modelling is a technique that is widely known and it is a part of operations research. Executives, engineers or scientists in many organizations have applied the optimization method in various aspects such as allocating resources in which the factors or resources are the raw materials, manpower, time, place, currency or knowledge. Problems in allocating factors and resources occur when we want to allocate resources that are limited in size, quantity and scope of use. For maximizing benefits, the optimization is a technique for solving the problems of allocating factors and resources that are related to various variables with the aim to solve problems and make decisions based on the optimal practices such as maximum profit, the least cost, or other guidelines that provide the most benefits to that system by considering the conditions or restrictions imposed such as market conditions, shortage of raw materials, manpower, capital, places, knowledge, legal requirements and various social regulations, management policy, the scope of the existing business and others for example using linear programming techniques to solve problems in transportation which is related to various types of products, product weight and size, freight price, manpower used in driving with limitations such as the quantity and size of the existing cars, weight of goods that can be loaded per trip, the amount of market demand, capital, time constraints on shipping. In addition, linear programming has been used to solve production problems in various industries which must be directly related to various types of raw materials used in production, types of machinery, manpower, selling price, and marketing with various conditions such as production capability of machines and labor, market demand, the amount of raw materials and other energy in production such as water, electricity, wood that are limited, and also the amount of funds which is limited. The optimization technique in this research is developed based on scientific progress which has been initiated by many scientific mathematicians which the theory has been used in Game Theory including being developed and used in transportation. Moreover, such technique also has been used to solve nutritional problems. Later, using mathematics and related techniques to solve problems in the project planning in the army.
Nowadays, it is accepted in many fields to apply the linear programming technique in many aspects such as agriculture, economics, production management, and industry by creating a mathematical model as follows:

$$
\begin{aligned}
& \min z=f(x) \\
& \text { s.t. } \quad g_{i}(x)=c_{i}, \forall \mathrm{i}=1, . ., \mathrm{n} \\
& h_{j}(x) \leq d_{j}, \forall \mathrm{j}=1, . ., \mathrm{m} \\
& x \in R^{n_{x}}
\end{aligned}
$$

By specifying the decision variable $x \in R^{n_{x}}$ to be the real and continuous number for $f(x)$ as the target equation of the problem that can have the direction to find the maximization or minimization depends on the type of problem that needs to be applied. The Eq. (2) $g_{i}(x)=c_{i}$ is a function in the form that has an equal sign as an assembly. The inequality $(3) h_{j}(x) \leq$ $d_{j}$ is a conditional inequality used to determine the problem. For example, the number of passengers must be less than or equal to the capacity of a highspeed train. In summa. The optimization is composed of 3 parts: 1( Input data such as limitations of various problems that affect the selection of the best decision variables or information related to the target equation such as unit price. 2) Mathematical model determines problems that we want to find out the answers in the form of mathematical relationships. 3) Output will show the answer of the equation system that we have created which will be the best answer under various limitations. Some recent relevant researches apply optimization modeling to the train application. [2026] uses optimization model to find the optimal timetable for train schedules.

This research aims to create a mathematical model that is a simulation under certain conditions (Deterministic Dynamic Model) that can analyze flexible fares. This mathematical model will consist of decision variables, objective functions, various restrictions. This mathematical model will be created in optimization software and find the best answer by using the system to find the optimal answer (Solver) of the program itself. The greatest advantage in creating this model is able to analyze various things in "what-if" scenarios with high speed railway systems in Thailand in many ways.

\subsection{Studying pricing fares in various countries}

\subsubsection{Studying pricing fares in Various Countries}

The implementation of high-speed trains around the world that provide services to the public has one 
Table 1. Factors affect high speed train fares

\begin{tabular}{|l|c|c|c|c|c|}
\hline & Distance & $\begin{array}{c}\text { Express } \\
\text { Service }\end{array}$ & $\begin{array}{c}\text { Time of } \\
\text { purchasing tickets }\end{array}$ & $\begin{array}{c}\text { Type of passenger } \\
\text { compartment }\end{array}$ & Traveling time \\
\hline China & $\mathrm{X}$ & $\mathrm{X}$ & & $\mathrm{X}$ & \\
\hline Japan & $\mathrm{X}$ & & & $\mathrm{X}$ & \\
\hline South Korea & $\mathrm{X}$ & & & $\mathrm{X}$ & \\
\hline Taiwan & $\mathrm{X}$ & $\mathrm{X}$ & $\mathrm{X}$ & $\mathrm{X}$ & $\mathrm{X}$ \\
\hline France & $\mathrm{X}$ & & $\mathrm{X}$ & $\mathrm{X}$ & $\mathrm{X}$ \\
\hline Germany & $\mathrm{X}$ & & $\mathrm{X}$ & $\mathrm{X}$ & $\mathrm{X}$ \\
\hline Spain & $\mathrm{X}$ & & $\mathrm{X}$ & $\mathrm{X}$ & $\mathrm{X}$ \\
\hline Switzerland & $\mathrm{X}$ & & $\mathrm{X}$ & $\mathrm{X}$ & $\mathrm{X}$ \\
\hline UK & $\mathrm{X}$ & & $\mathrm{X}$ & $\mathrm{X}$ & $\mathrm{X}$ \\
\hline USA & $\mathrm{X}$ & $\mathrm{X}$ & $\mathrm{X}$ & $\mathrm{X}$ & $\mathrm{X}$ \\
\hline
\end{tabular}

important objective that is reducing unnecessary investments in public transport infrastructure. In addition, high-speed rail operations in some countries such as Taiwan and South Korea, and Spain aims at facilitating and spreading prosperity. In terms of fare collection, each country has different fare collection policies.

Asian countries with high-speed rail systems including China, Japan, South Korea, and Taiwan have different fare collection policies such as fares for HSR in China and Taiwan depending on the number of kilometers traveled, fares for high-speed trains in Japan called Shinkansen not only depending on the number of kilometers traveled but there are also additional fees for express services depending on the distance traveled, fares for South Korea's highspeed trains or Korea Train Express are reduced by the number of kilometers traveled. More countries in Europe with high-speed rail systems are France, Germany, Spain, Italy, Sweden, and Switzerland. Ticket fares for trains in France, Train à Grande Vitesse (TGV), and Spain, Alta Velocidad Española (AVE), are unlike Asian countries because there are factors such as booking time, distance traveled, train type, and time of travel. Fares for high-speed trains in Germany depends on the distance but the train fares in the United Kingdom will depend on booking time and a time of booking a coach. However, in the United States will use the floating ticket policy which will depend on the time of ticket purchase. Factors affect the price of high-speed train in various countries can be divided as detailed in Table 1 .

To summarize the pricing of high-speed train tickets that varies in each country. Fares for highspeed train tickets in Asia consist of the base rate multiplied by the number of kilometers traveled and vary according to the number of passengers $[18,19]$. While Europe and the United States apply floating fares. Other factors which are not mentioned in the service provider's perspective that influence on ticket

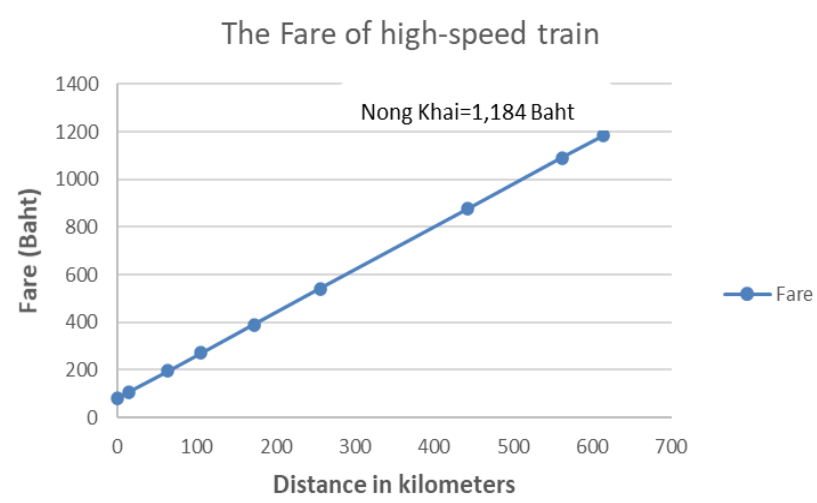

Figure. 2 Shows the fares of high-speed trains

prices in general are transportation costs, profit margins, passenger capacity, and comparison with fares from other transportation modes.

\subsubsection{The concept of pricing fares for high-speed trains in thailand}

To plan fares and schedule train timetable, the government plans to collect fares starting at 80baht (Fixed Rate) and adding 1. 8baht per kilometer (Variable Rate) such as fare by traveling from Bangkok to Nakhon Ratchasima is equal to $80+1.8$ 256.2( $=541$. 2baht. The picture shows the fare from Bangkok to Nakhon Ratchasima, Khon Kaen, Udon Thani and Nong Khai which can be considered as a straight-line fare setting as shown in Fig. 2, i.e.

$$
\begin{gathered}
\text { Fare }=\text { Fixed rate }+ \text { Distance in kilometers X } \\
\text { Variable rate per kilometer }
\end{gathered}
$$

The fare rate will follow this format. For the fare adjustment, it will increase by 15 percent every 5 years due to the forecast of the passenger volume. The government has planned to operate the train with stops at every station, providing a service with a maximum speed of 250 kilometers/hour with the distance of 253kilometers in 6stations and stops for 2 minutes at each station, total travel time is about 1 hour 30minutes. The service period is $6.00-22.00$ 
hrs. or 16 hours per day. In the first year of service (year 2021), there will be 11 trains per day per direction with a service frequency of 90 minutes/train.

Based on the calculation mentioned above We can conclude that the pricing for Thailand system is a fixed base price added with distance traveled however literatures theoretically confirm that an advance-purchase discount based on stochastic demand can facilitate in reaching efficient allocation of capacity []. The objectives of this work are to construct a mathematical model that helps Railsystem to maximize total expected profit. Also, the model should determine the optimal prices for different time opurchases. In particular, the study should answer the following questions:

- What are the optimal prices for each origin destination?

- How to set the prices respected to demand changes?

The questions listed above are overly complex to be solved simultaneously, and therefore they must be addressed with the use of the optimization programming. For the pricing policy level, this paper wishes to determine the optimal prices in order to maximize the sum of expected profit and satisfying all demands.

\section{Conceptual framework for system design in determining dynamic fares for the high-speed rail system in Thailand}

Dynamic Pricing Optimizer (DPO) is a unique system of dynamic pricing by considering the changes in the amount of service requirements and the time of purchasing tickets designed to solve the problem of pricing that is appropriate. The Dynamic Pricing Optimizer (DPO) system will integrate the user data from the latest trip or historical information.
After that, there will be a forecast for users of highspeed trains based on historical data in order to create a demand function that is linear. After that, the price will be determined by the optimization method to find the most suitable price. The DPO system is designed by using IT technology combined with the mathematical model. The system consists of the following parts.

- DPO1- Demand Forecasting Module

- DPO2- Dynamic Pricing Module

The work of the DPO system will start from the calculation. The number of users in the DPO1 Demand Forecasting Module which uses the historical data of the high-speed train users as input. After that, the number of passengers will be predicted to be sent to DPO2 - Dynamic Pricing Module. The DPO2 model will use the forecasting of passengers as input data to be analyzed through the process of finding the optimal condition (Optimization) until getting the dynamic fare rate that will change according to the number of users and service capability. Fig. 3 shows the system architecture design and data flow data of the DPO system.

\subsection{Demand forecasting module (DPO1)}

DPO1 - Demand Forecasting Module has a designing concept by using statistical model. It uses historical data from the users of high-speed train as input. After that, the number of passengers will be predicted to be sent to the DPO2 - Dynamic Pricing Module. The system design principle is shown in Fig. 3.

The operation of DPO1 will use the Predictive Analytic Model to predict by using linear regression to create a model for forecasting. The most important thing in DPO1's operation is to choose a data set to test the model.

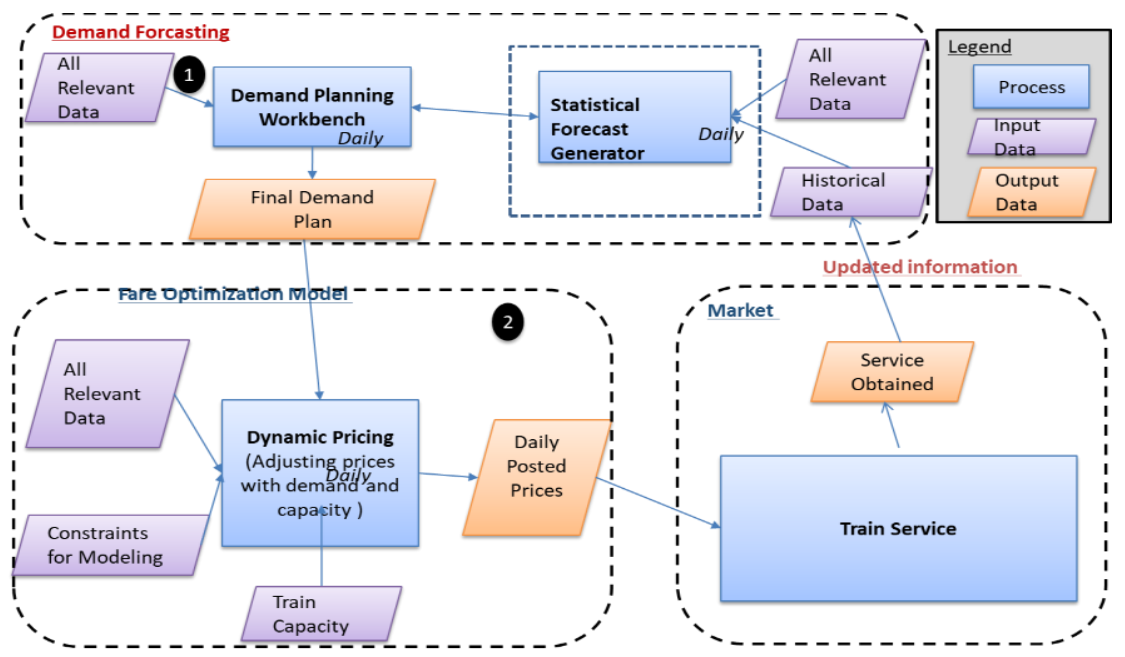

Figure. 3 Dynamic pricing optimizer (DPO) system 

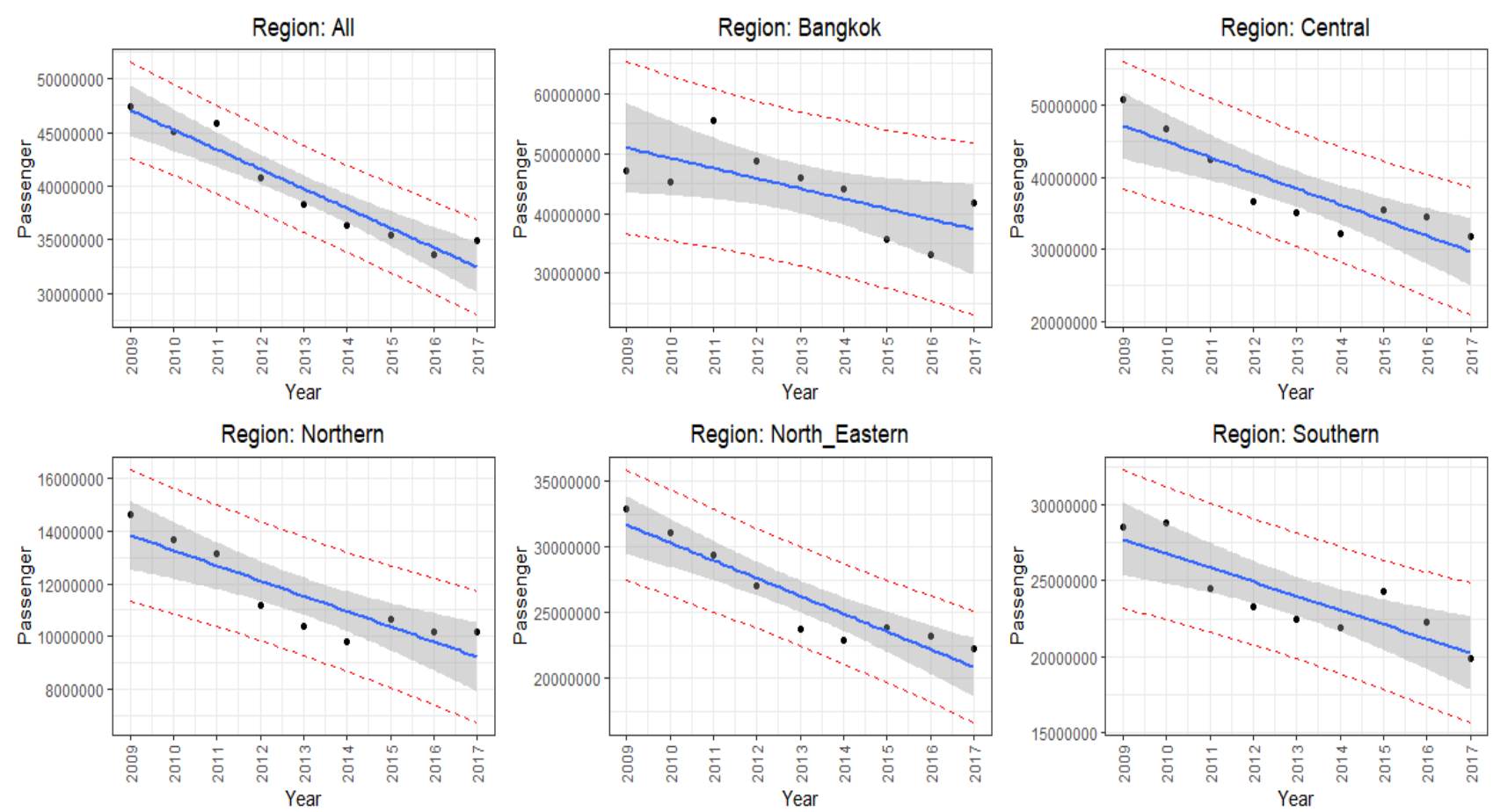

Figure. 4 Output from demand forecasting module using python

However, the high-speed rail project in Thailand is not yet available because the service is not yet opened. The research team therefore used the information of traveling by regular train which will be the number of passengers in the provinces and districts in the fiscal year 2009 - 2017 from the State Railway of Thailand, Ministry of Transport to test the models used in forecasting. Therefore, the research team created DPO2 in the Python program which is a free open source. The test will use the data which is a number of passengers in the fiscal year 2009 - 2017 to analyze by using the code written in the Phyton program and Linear Regression in the analysis because the data is only the number of people per year that should not use other techniques because they want to it be easy and good for training and testing error.

The results of the analysis are shown in Fig. 4.12 and can be displayed in a straight-line graph where the blue line is the Linear Prediction Model, the gray area is the confidence intervals (95\% confidence intervals), the red line is $95 \%$ prediction intervals. The model can predict the passenger volume per year in the next year (in the year 2018) with different accuracy according to the historical data as shown in Table 4.7 which specifies the accuracy level of forecasting is at $40 \%-88 \%$ depending on the nature of the data. For northeast data, the accuracy is $88.71 \%$. However, in actual use, this model must be applied to predict the amount of demand each week or can be used as a daily demand. When forecasting, the data will be sent to the DPO2 accordingly.

\subsection{Dynamic pricing module (DPO2)}

For the calculation in part 2 of this research, it will be calculated to determine the dynamic piecewise pricing policy with the forecasting demand in each service period. To determine the price by the period, the price will be set at the same price per time in each origin and destination instead of constantly changing prices which is complex and may not be suitable for reality in practice. Operation characteristics is shown in Fig. 3.

\section{Input parameters:}

$C_{i} \quad$ The maximum passenger capacity of the service $i$

$T_{j} \quad$ Number of sub-periods used in ticket sales $j$

$d_{j}^{t} \quad$ Period of sub-period $t$ of the service $j$

$\lambda_{j}^{t} \quad$ The density of the amount of demand for the service $j$ in the period $t$

$p_{j}^{0} \quad$ Based price of the service $j$

$\alpha \quad$ The lowest fluctuation ratio of the price

$\beta \quad$ The highest fluctuation ratio of the price

\section{Decision variables}

$p_{j}^{t} \quad$ The price of the service $j$ in the period $t$

$r_{j}^{t} \quad$ Income rate of the service $j$ in the period $t$ 


\section{Objective function:}

$$
\operatorname{Min} \mathrm{R}(\lambda)=\sum_{j} \sum_{t} a_{i j} p_{j}^{t}(\lambda) \mathrm{d}_{j}^{t}
$$

The target equation aims to find the highest revenue from the ticket sales price set at the most specified time produced by all products during the sale of all tickets. This research hypothesizes the sale of tickets as first come, first serve.

\section{Constraint equations}

$$
\begin{gathered}
\sum_{j} \sum_{t} a_{i j} \lambda_{j}^{t} \mathrm{~d}_{j}^{t} \leq C_{i}, \quad \forall i \in I \\
(1-\alpha) p_{j}^{0} \leq p_{j}^{t}(\lambda) \leq(1+\beta) p_{j}^{0}, \forall t, j
\end{gathered}
$$

Eq. (6) is a limitation equation that limits the number of ticket bookings to not exceed the capacity or ability to provide services in each type of service. Eq. (7) defines the range of price fluctuations by having the lower limit based on the cost of transportation services and the upper limit based on psychological criteria of passengers.

Demand function and price in this research are log-linear demand functions that explain the relationship between the demand for high-speed rail services and the price as having the following relationship.

$$
\lambda(p)=\lambda^{0} e^{-\varepsilon^{\Im}\left(\frac{p}{p^{0}}-1\right)}
$$

$p^{0}$ is the base price, $\lambda^{0}$ is the demand density when the price is defined as the base price and the $\varepsilon^{\nabla}$ is the absolute value of the price elastic of demand. The above relationship can find inverse function as follows.

$$
p(\lambda)=\left(\frac{1}{\varepsilon_{0}} \ln \left(\frac{\lambda^{0}}{\lambda}\right)+1\right) p^{0}
$$

Table 2. Shows pairs of stations that are in contact with each other

\begin{tabular}{|c|c|}
\hline & index $\boldsymbol{i}$ (pairs of consecutive stations) \\
\hline 1 & Bang Sue - Don Mueang \\
\hline 2 & Don Mueang - Ayutthaya \\
\hline 3 & Ayutthaya - Saraburi \\
\hline 4 & Saraburi - Pak Chong \\
\hline 5 & Pakchong - Nakhon Ratchasima \\
\hline 6 & Nakhon Ratchasima - Khon Kaen \\
\hline 7 & Khon Kaen - Udon Tani \\
\hline 8 & Udon Tani - Nong khai \\
\hline
\end{tabular}

$\varepsilon^{2}$ is the price elastic of demand that is the ratio of percentage in demand change compared to the ratio of percentage in price change as the calculation below.

$$
\varepsilon^{0}=\frac{\text { the ratio of purchase quantity change }}{\text { the ratio of service price change }}
$$

In this research, it will be compared with other types of transportation services in each pair of origins and destinations.

\section{Case study: bangkok - nong khai high- speed train}

The next step is to test the mathematical model applied to the high-speed rail system of Thailand, Bangkok-Nong Khai route in order to find the right dynamic range price by using such a model. In the first step, it will prepare the import data that will be used for all tests. For the high-speed rail system in Thailand, there are 9 stations including Bang Sue Station, Don Mueang Station, Ayutthaya Station, Saraburi Station, Pak Chong Station, Nakhon Ratchasima Station, Khon Kaen Station, Udon Thani Station and Nong Khai Station. The first part of the data that we have to prepare is the index data $\mathrm{i}$ which is a pair of consecutive stations which will be set in pairs such as Bang Sue Station - Don Mueang Station, Udon Station - Nong Khai Station etc. Table 2 shows the pair of stations that are in contact with each other.

The subsequent data to be prepared is the index data $j$ that is every possible pair of stations which will be set in pairs such as Bang Sue Station - Don Mueang Station, Udon - Nong Khai Station, and etc. Table 3 shows all possible station pairs. Other import data used in the model are base price information, the period information of service sub-period $d_{j}^{t}$, the density of the amount of demand in that time $\lambda_{j}^{t}$ as shown in Table 4.

\section{Results from the mathematical model written in the LINGO program}

In the mathematical model test, the researcher used the LINGO program by comparing between the traditional fare collection periodic dynamic policy by setting the service capacity of the train in each trip at 800 people and dividing the ticket purchasing time into 3 periods and the demand density from the first period $(\mathrm{t}=1)$ until the last moment before the train departs $(t=3)$ equals $5 \%$. In a term of the base price, the price determined by the traditional policy is used as the basis for calculating the amount of demand. 
Table 3. Shows pairs of stations that are in contact with each other

\begin{tabular}{|c|c|c|c|}
\hline \multicolumn{4}{|c|}{ Station Indexes } \\
\hline 1 & Bang Sue-Don Mueang & 19 & Ayutthaya_KhonKaen \\
\hline 2 & Bang Sue-Ayutthaya & 20 & Ayutthaya_UdonTani \\
\hline 3 & Bang Sue-Saraburi & 21 & Ayutthaya_Nong khai \\
\hline 4 & Bang Sue_Pakchong & 22 & Saraburi_Pakchong \\
\hline 5 & Bang Sue_NakhonRatchasima & 23 & Saraburi_NakhonRatchasima \\
\hline 6 & Bang Sue_KhonKaen & 24 & Saraburi_KhonKaen \\
\hline 7 & Bang Sue_UdonTani & 25 & Saraburi_UdonTani \\
\hline 8 & Bang Sue_Nong khai & 26 & Saraburi_Nong khai \\
\hline 9 & Don Mueang_Ayutthaya & 27 & Pakchong_NakhonRatchasima \\
\hline 10 & Don Mueang_Saraburi & 28 & Pakchong_KhonKaen \\
\hline 11 & Don Mueang_Pakchong & 29 & Pakchong_UdonTani \\
\hline 12 & Don Mueang_NakhonRatchasima & 30 & Pakchong_Nong khai \\
\hline 13 & Don Mueang_KhonKaen & 31 & NakhonRatchasima_KhonKaen \\
\hline 14 & Don Mueang_UdonTani & 32 & NakhonRatchasima_UdonTani \\
\hline 15 & Don Mueang_Nong khai & 33 & NakhonRatchasima_Nong khai \\
\hline 16 & Ayutthaya_Saraburi & 34 & KhonKaen_UdonTani \\
\hline 17 & Ayutthaya_Pakchong & 35 & KhonKaen_Nong khai \\
\hline 18 & Ayutthaya_NakhonRatchasima & 36 & UdonTani_Nong khai \\
\hline
\end{tabular}

Table 4. Input data for calculation

\begin{tabular}{|c|c|c|c|c|c|c|c|}
\hline & \multicolumn{3}{|c|}{$t=1$} & \multicolumn{4}{|c|}{$t=1$} \\
\hline & Po & $d_{j}^{t}$ & $\lambda_{j}^{t}$ & & Po & $d_{j}^{t}$ & $\lambda^{t}$ \\
\hline $\mathrm{J}=1$ & 106.46 & 303 & 0.029 & $\mathrm{~J}=19$ & 761.66 & 303 & 0.029 \\
\hline $\mathrm{J}=2$ & 194.48 & 96 & 0.122 & $\mathrm{~J}=20$ & 976.04 & 96 & 0.122 \\
\hline $\mathrm{J}=3$ & 270.44 & 68 & 1.481 & $\mathrm{~J}=21$ & 1070.18 & 68 & 1.481 \\
\hline $\mathrm{J}=4$ & 390.5 & 231 & 0.033 & $\mathrm{~J}=22$ & 200.06 & 231 & 0.033 \\
\hline $\mathrm{J}=5$ & 541.16 & 168 & 0.077 & $\mathrm{~J}=23$ & 350.72 & 168 & 0.077 \\
\hline $\mathrm{J}=6$ & 876.14 & 68 & 0.982 & $\mathrm{~J}=24$ & 685.7 & 68 & 0.982 \\
\hline $\mathrm{J}=7$ & 1090.52 & 303 & 0.029 & $\mathrm{~J}=25$ & 900.08 & 303 & 0.029 \\
\hline $\mathrm{J}=8$ & 1184.66 & 96 & 0.122 & $\mathrm{~J}=26$ & 994.22 & 96 & 0.122 \\
\hline $\mathrm{J}=9$ & 168.02 & 68 & 1.481 & $\mathrm{~J}=27$ & 230.66 & 68 & 1.481 \\
\hline $\mathrm{J}=10$ & 243.98 & 231 & 0.033 & $\mathrm{~J}=28$ & 565.64 & 231 & 0.033 \\
\hline $\mathrm{J}=11$ & 364.04 & 168 & 0.077 & $\mathrm{~J}=29$ & 780.02 & 168 & 0.077 \\
\hline $\mathrm{J}=12$ & 514.7 & 68 & 0.982 & $\mathrm{~J}=30$ & 874.16 & 68 & 0.982 \\
\hline $\mathrm{J}=13$ & 849.68 & 303 & 0.029 & $\mathrm{~J}=31$ & 414.98 & 303 & 0.029 \\
\hline $\mathrm{J}=14$ & 1064.06 & 96 & 0.122 & $\mathrm{~J}=32$ & 629.36 & 96 & 0.122 \\
\hline $\mathrm{J}=15$ & 1158.2 & 68 & 1.481 & $\mathrm{~J}=33$ & 723.5 & 68 & 1.481 \\
\hline $\mathrm{J}=16$ & 155.96 & 231 & 0.033 & $\mathrm{~J}=34$ & 294.38 & 231 & 0.033 \\
\hline $\mathrm{J}=17$ & 276.02 & 168 & 0.077 & $\mathrm{~J}=35$ & 388.52 & 1.05 & 0.077 \\
\hline $\mathrm{J}=18$ & 426.68 & 68 & 0.982 & $\mathrm{~J}=36$ & 174.14 & 0.95 & 0.982 \\
\hline
\end{tabular}


Table 5. Comparison table of revenue results in both policies

\begin{tabular}{|l|l|l|}
\hline & $\begin{array}{l}\text { Original } \\
\text { Policy }\end{array}$ & $\begin{array}{l}\text { Dynamic Pricing } \\
\text { Policy }\end{array}$ \\
\hline $\begin{array}{l}\text { Revenue } \\
\text { (Baths) }\end{array}$ & $1,494,169.96$ & $1,592,525.06$ \\
\hline
\end{tabular}

From Table 5 found that the original fare collection policy would be able to collect the total revenue of 1,494,169.96 baht but the dynamic fare collection policy would be able to collect the total revenue of 1592556 with the difference of income at $98,355.11$ baht. Table 6 shows the price results in the time of the ticket distribution that is divided into 3 periods. The example of the comparison is the travel from Bang Sue station to Nong Khai station. The original policy price will be at 1,185 baht but in the periodic dynamic fare collection policy, there will be a total of 3 prices, i.e. if the passenger booked the ticket in advance for a period of time $(t=1)$, the fare that passengers will pay is $1,101.73$ baht. Besides, if booking a ticket in the period $(\mathrm{t}=2)$, the passenger must pay the fare at 1,160.96 baht. Furthermore, if booking in the short time when the train almost departs $(t=3)$, the fare will be issued at 1,303.1 baht. When comparing with the base price from the original policy, the price from the periodic dynamic policy in the period $t=1, t=2$ will be cheaper than the base price equal to $7.03 \%$ and $2.03 \%$ respectively. However, for the time $t=3$, the price from the periodic dynamic policy will be higher than the base price which is $9.97 \%$.

According to the comparison results of both policies can be concluded that the prices from periodic dynamic policy will make pricing more flexible than traditional pricing. The fares for those who book in advance for a long period of time will be cheaper than the original price about $2-7 \%$ but if books at a short time, the fare will be about $5 \%-10 \%$ more expensive. In terms of income, when having the same amount of demand and the same pattern, it will provide about $6.5 \%$ better results. The other advantage is a factor that makes the service users have more advance planning in order to obtain a ticket at a cheaper price than a short-time purchase. It will be beneficial to service providers because they will be able to plan existing resources efficiently and maximize benefits.

As indicated above dynamic pricing can drive prices in both directions. The prices can increase to capitalise on demand, but they can also lower to try and increase sales. In this case, the lower prices due to early booking will encourage the passengers to book a ticket early and plan their trip ahead. Therefore, some economic benefit is there for a
Table 6. Price results from the model

\begin{tabular}{|c|c|c|c|}
\hline & $\mathbf{T}=\mathbf{1}$ & $\mathbf{T}=\mathbf{2}$ & $\mathbf{T}=\mathbf{3}$ \\
\hline Bang Sue-Don Mueang & 99.00 & 104.33 & 117.10 \\
\hline Bang Sue-Ayutthaya & 180.86 & 190.59 & 213.92 \\
\hline Bang Sue-Saraburi & 251.50 & 265.03 & 297.48 \\
\hline Bang Sue-Pakchong & 363.16 & 382.69 & 429.55 \\
\hline $\begin{array}{l}\text { Bang Sue- } \\
\text { NakhonRatchasima }\end{array}$ & 503.27 & 530.33 & 595.27 \\
\hline Bang Sue-KhonKaen & 814.81 & 858.61 & 963.75 \\
\hline Bang Sue-UdonTani & 1014.1 & 1068.7 & 1199.5 \\
\hline Bang Sue-Nong khai & 1101.7 & 1160.9 & 1303.1 \\
\hline $\begin{array}{ll}\text { Don } & \text { Mueang- } \\
\text { Ayutthaya }\end{array}$ & 156.25 & 164.65 & 184.82 \\
\hline Don Mueang-Saraburi & 226.90 & 239.10 & 268.37 \\
\hline Don Mueang-Pakchong & 338.55 & 356.75 & 400.44 \\
\hline $\begin{array}{l}\text { Don Mueang- } \\
\text { NakhonRatchasima }\end{array}$ & 478.67 & 504.40 & 566.17 \\
\hline $\begin{array}{ll}\text { Don } & \text { Mueang- } \\
\text { KhonKaen } & \\
\end{array}$ & 790.20 & 832.68 & 934.64 \\
\hline $\begin{array}{ll}\text { Don } & \text { Mueang- } \\
\text { UdonTani } & \\
\end{array}$ & 989.57 & 1042.7 & 1170.4 \\
\hline $\begin{array}{l}\text { Don Mueang_Nong } \\
\text { khai }\end{array}$ & 1077.1 & 1135.0 & 1274.0 \\
\hline Ayutthaya-Saraburi & 145.04 & 152.84 & 171.55 \\
\hline Ayutthaya-Pakchong & 256.69 & 270.49 & 303.62 \\
\hline $\begin{array}{l}\text { Ayutthaya- } \\
\text { NakhonRatchasima }\end{array}$ & 396.81 & 418.14 & 469.34 \\
\hline Ayutthaya-KhonKaen & 708.34 & 746.42 & 837.82 \\
\hline Ayutthaya-UdonTani & 907.71 & 956.51 & 1073.6 \\
\hline Ayutthaya-Nong khai & 995.26 & 1048.7 & 1177.1 \\
\hline Saraburi-Pakchong & 186.05 & 196.05 & 220.0 \\
\hline $\begin{array}{l}\text { Saraburi- } \\
\text { NakhonRatchasima }\end{array}$ & 326.16 & 343.70 & 385.7 \\
\hline Saraburi-KhonKaen & 637.70 & 671.98 & 754.2 \\
\hline Saraburi-UdonTani & 837.07 & 882.07 & 990.0 \\
\hline Saraburi-Nong khai & 924.62 & 974.33 & 1093. \\
\hline $\begin{array}{l}\text { Pakchong- } \\
\text { NakhonRatchasima }\end{array}$ & 214.51 & 226.04 & 253.7 \\
\hline Pakchong-KhonKaen & 526.04 & 554.32 & 622.2 \\
\hline Pakchong-UdonTani & 725.41 & 764.41 & 858.0 \\
\hline Pakchong-Nong khai & 812.96 & 856.67 & 961.5 \\
\hline $\begin{array}{l}\text { NakhonRatchasima- } \\
\text { KhonKaen }\end{array}$ & 385.93 & 406.68 & 456.4 \\
\hline $\begin{array}{l}\text { NakhonRatchasima- } \\
\text { UdonTani }\end{array}$ & 585.30 & 616.77 & 692.2 \\
\hline $\begin{array}{l}\text { NakhonRatchasima- } \\
\text { Nong khai }\end{array}$ & 672.85 & 709.03 & 795.8 \\
\hline KhonKaen-UdonTani & 273.77 & 288.49 & 323.8 \\
\hline KhonKaen-Nong khai & 361.32 & 380.74 & 427.3 \\
\hline UdonTani-Nong khai & 161.95 & 170.66 & 191.5 \\
\hline
\end{tabular}


comparatively more, if passengers book on a closer date. Dynamic pricing aims for the revenue maximization based on the demand and supply. Even though the demand is less, railway charges premium pricing from the customers.

\section{Summary of the research results and discussion}

This paper examines The Dynamic Pricing Optimizer (DPO) system with the Bangkok-Nong Khai high-speed rail system. The design system consists of 2 important parts as follows.

- DPO1- Demand Forecasting Module

- DPO2- Dynamic Pricing Module

DPO1 can calculate user forecasting. In this research uses the historical data of the number of passengers from the year 2009 to 2017, the model used will have the accuracy of $88.7 \%$ which can be considered to have a certain level of an accuracy. After that, the number of forecasted passengers will be sent to the DPO2 model.

In the next step, DPO2 will calculate the appropriate train schedule by using optimization which has the result of global optimal. The price will be based on the dynamic piecewise pricing policy and forecasting demand by determining that price range with only one price per period in each origin and destination.

Our goal is to maximize the expected revenue of high-speed train by setting multiple ticket prices according to different time of purchases.

The pricing for fairness and attracting customers to use the service is one of the factors influencing the success of the country's strategic investment by using high-speed rail systems as a driver. The pricing policy is very important. because it directly affects consumers and service providers. If the price is not suitable, the service provider will suffer losses but if the price is too expensive, the consumers may not be able to use the service because of the problem of excessive price. Therefore, to set the price policy appropriately is so important not less than other operations. In addition, from the study of this research data, it was found that the pricing policy for high-speed train fares in different countries around the world varies from country to country.

Although the application of dynamic pricing in the high-speed rail system in Thailand will be quite difficult. The main reason is that the service users or most people prefer fixed prices rather than allowing prices to change frequently. Another important reason is that there must be corrections or adjustments to the regulations of State Railway of
Thailand to be appropriate and more concise if want to apply a dynamic price system. The proposed technique can be applied to other railway systems if the pricing policy allows multiple fare prices and flexible timetable schedule.

There are many possible directions for future research in this area. The optimization model in this paper is a deterministic however applying stochasticity to demands will be more realistic.

\section{Conflicts of Interest}

The authors declare no conflict of interest.

\section{Author Contributions}

Kankanit Khwanpruk Conceptualization; Chalida U-tapao methodology; Somkiat Khwanpruk model builder; Laemthong Laokhongthavorn validation; Seksun Moryadee writing - original draft preparation.

\section{Acknowledgments}

This research was funded by KMITL Research and Innovation funding for High-Speed Train Advance Study.

\section{References}

[1] Dynamic Pricing definition. WhatIs.com. Retrieved April 1, 2018.

[2] A. Shpanya, "Why Dynamic Pricing is a Must for eCommerce Retailers", econsultancy.com. Retrieved April 1, 2018.

[3] W. Elmaghraby and P. Keskinocak, "Dynamic Pricing in the Presence of Inventory Considerations: Research Overview, Current Practices, and Future Directions", IEEE Engineering Management Review, Vol. 31, No. 4, pp. 47- 47, 2003.

[4] N. Irwin, "Why Surge Prices Make Us So Mad: Wh at Springsteen, Home Depot and a NobelWinner Know", New York Times, Nytimes.com, 2017, Retrieved April 16, 2018.

[5] A. Clements, "Yemen's other crisis - the daily struggle for food", The Guardian, 2011 www.theguardian.com, Retrieved April 16, 2018.

[6] T. Cummings, "Everything You Need to Know about Dynamic Pricing", 7learnings.com,2013. Retrieved April 16, 2018.

[7] M. Labbé, P. Marcotte, and G. Savard, "A Bilevel Model of Taxation and Its Application to Optimal Highway Pricing", Management Science, Vol. 1, No. 12, pp. 1608-1622, 1998. 
[8] K. V. Dender, "Pricing Transport Networks with Fixed Residential Location", Regional Science and Urban Economics, Vol. 34, No. 3, pp. 289307, 2004

[9] L. S. Buriol, M. J. Hirsch, P. M. Pardalos, T. Querido, M. G. C. Resende, and M. Ritt, "A Biased Random-Key Genetic Algorithm for Road Congestion Minimization", Optimization Letters, Vol. 4, No. 4, pp. 619-633, 2010.

[10] T. V. Woensel and F. Cruz, "A Stochastic Approach to Traffic Congestion Costs", Computers \& Operations Research, Vol. 36, No. 6, pp. 1731-1739, 2009.

[11] E. T. Verhoef, "Second-Best Congestion Pricing in General Static Transportation Networks with Elastic Demands", Regional Science and Urban Economics, Vol. 32, pp. 281-310, 2002

[12] B. Adenso-Diaz, M. Oliva González, M. O., and P. González-Torre., "On-Line Timetable ReScheduling in Regional Train Services", Transportation Research Part B: Methodological, Vol. 33, No. 6, pp. 387-398, 1999

[13] I. Sahin, "Railway Traffic Control and Train Scheduling Based on Inter-Train Conflict Management", Transportation Research Part B: Methodologica, Vol. 33, No. 7, pp. 511-534, 1999

[14] M. Freyss, R. Giesen, and J. C. Muñoz, "Continuous Approximation for Skip-Stop Operation in Rail transit", Procedia - Social and Behavioral Sciences, Vol. 80, pp. 186-210, 2013

[15] U. Brännlund, P. O. Lindberg, A. Nõu, and J. E. Nilsson, "Railway Timetabling Using Lagrangian Relaxation", Transportation Science, Vol. 32, No. 4, pp. 358-369, 1998

[16] A. D'Ariano, D. Pacciarelli, and M. Pranzo, "Assessment of Flexible Timetables in Real Time Traffic Management of a Railway Bottleneck", Transportation Research Part C: Emerging Technologies, Vol. 2, pp. 232- 245, 2008

[17] Y. Lee and C. Y. Chen, "A Heuristic for the Train Pathing and Timetabling Problem", Transp. Res. Part B: Methodol, Vol. 43, No. 8, 837-851, 2009

[18] C.-L. Chen and P. Hall, "The impacts of highspeed trains on British economic geography: a study of the UK's InterCity $125 / 225$ and its effects", J. Transport Geogr., Vol. 19, No. 4, 689-704, 2011.

[19] J. Zheng and J. Liu, "The Research on Ticket Fare Optimization for China's High-Speed Train", Mathematical Problems in Engineering, Vol. 2016, Article ID 5073053, 2016.
[20] P. Shang, R. Li, and L. Yang, "Demand-driven timetable and stop pattern cooperative optimization on an urban rail transit line", Transportation Planning and Technology, Vol. 4, No. 1, p. 78-100, 2020.

[21] Y. Y. Tan, Z. B. Jiang, Y. X. Li, and R. X. Wang, "Integration of Train-Set Circulation and Adding Train Paths Problem Based on an Existing Cyclic Timetable", IEEE Access, Vol. 8, pp. 87142-87163, 2020.

[22] X. Dong, D. Li, Y. Yin, S. Ding, and Z. Cao, "Integrated optimization of train stop planning and timetabling for commuter railways with an extended adaptive large neighborhood search Metaheuristic approach", Transportation Research Part C: Emerging Technologies, Vol. 117, p.102681, 2020.

[23] E. Hassannayebi, M. Boroun, S. A. Jordehi, and H. Kor, "Train schedule optimization in a highspeed railway system using a hybrid simulation and meta-model approach", Computers \& Industrial Engineering, Vol. 138, p. 106110, 2019.

[24] J. Xie, S. C. Wong, S. Zhan, S. M. Lo and A. Chen, "Train schedule optimization based on schedule-based stochastic passenger assignment", Transportation Research Part E: Logistics and Transportation Review, Vol. 136, p. 101882, 2020.

[25] M. Boroun, S. Ramezani, N. V. Farahani, E. Hassannayebi, S. Abolmaali, and $M$. Shakibayifar, "An efficient heuristic method for joint optimization of train scheduling and stop planning on double-track railway systems", INFOR: Information Systems and Operational Research, Vol. 58, No. 4, pp. 652-679, 2020

[26] Y. Wang, D. Li, and Z. Cao, "Integrated timetable synchronization optimization with capacity constraint under time-dependent demand for a rail transit network", Computers \& Industrial Engineering, Vol. 142, p. 106374, 2020. 